\title{
CYCLE LANES: THEIR EFFECT ON DRIVER PASSING DISTANCES IN URBAN AREAS
}

\author{
Kathryn Stewart ${ }^{1}$, Adrian McHale ${ }^{2}$ \\ ${ }^{1}$ Transport Research Institute, Edinburgh Napier University, United Kingdom \\ ${ }^{2}$ RPS Group, Newark, United Kingdom
}

Submitted 8 November 2013; resubmitted 1 April 2014; accepted 16 May 2014

\begin{abstract}
The current literature in the field of cycle lanes has often shown contradictory evidence as to the benefits and risks of cycle lanes and previous work has specifically shown that on higher speed roads, drivers may pass closer to a cyclist when a cycle lane is present. Utilising an instrumented bicycle, we collected information as to the passing distance demonstrated by drivers when overtaking a cyclist within the urban $(30 \mathrm{mph} / 40 \mathrm{mph})$ environment. The presented analysis shows that when a driver encounters a cyclist mid-block (i.e. not at a junction), there are more significant variables than the presence of a cycle lane that determines the overtaking distance. The three most significant variables identified are: absolute road width, the presence of nearside parking and the presence of an opposing vehicle at the time of an overtaking manoeuvre. The analysis also demonstrated that there is a larger unknown factor when it comes to overtaking distances. We postulate that this unknown variable is the driver himself and will vary by area, site and even time of day (i.e. different driving cultures, congestion, or frustration during peak times, etc.) making it difficult to quantify.
\end{abstract}

Keywords: cycling; passing distance; instrumented bicycle; road safety; cycle lanes.

Reference to this paper should be made as follows: Stewart, K.; McHale, A. 2014. Cycle lanes: their effect on driver passing distances in urban areas, Transport 29(3): 307-316. http://dx.doi.org/10.3846/16484142.2014.953205

\section{Introduction}

The benefits of cycling as an effective form of transport are well known for both the individual and the greater population in terms of health, wealth and the environment and this fact is widely recognised and promoted at international, national and local levels of government.

In terms of health, it is widely recognised that obesity is a key risk factor for a number of conditions including heart disease, stroke, some cancers and type-2 diabetes. It is envisaged that without intervention obesity rates could be in excess of $40 \%$ by 2030 (Scottish Government 2009). In addition to the physical health problems caused by obesity, there can be a reduction in people's overall quality of life, which can lead to additional mental health problems. Lack of physical activity is seen as a major factor in modern lifestyles that contributes to these health problems and cycling may be part of the answer (Scottish Government 2010b). Furthermore, cycling has an important role to play in social inclusion; it enables a greater proportion of the population to afford travel to see friends and relatives. Beyond the rec- ognised personal wealth benefits cycling also has a significant role in the greater economy. For instance cyclists are generally fitter members of the population and are therefore less of a drain on the economy and more likely to contribute towards it. Furthermore, cycling has many positive externalities, for example, theoretically more people cycling results in fewer people contributing to road congestion (which itself may be limiting economic activity in some areas) and lower environmental impact (Cavill, Davis 2007). Currently both the UK and the Scottish governments have set the ambitious target of cutting net emissions by at least $80 \%$ by 2050 (compared to 1990 levels) (UK Parliament 2008; Scottish Parliament 2009). The UK government target was raised from $60 \%$ to $80 \%$ following recommendations set out by the Committee on Climate Change (Turner 2008) and the Scottish Government has furthermore, set an interim target of reducing emissions by at least $42 \%$ by 2020 .

Despite the wholesale recognised positives of cycling and policies aimed at its promotion, cyclists are widely perceived as belonging to one of the most vul- 
nerable road user groups and this may be influencing people's modal choice (Noland 1995; Parkin et al. 2007a, 2007b). For instance, whilst 15 million people own a bicycle, only 3.6 million use one regularly (Tolley 2008). This perception, unfortunately, may make the benefits and published targets difficult to attain; despite the long established fact that in the UK the benefits of regular cycling outweigh the loss of life years in cycling fatalities by a factor of around 20 to 1 (Cavill, Davis 2007). In attempts to mitigate the perceived risk council transport departments often automatically investigate the use of cycle lanes. Cycle lanes in the UK are either of the advisory (broken line) or mandatory (solid line) type and may be coloured or uncoloured. Whilst sufficiently designed cycle lanes may be seen to present a degree of visible separation from motorised vehicles, they may also restrict the free movement of cyclists by encouraging them to the left hand side of the road. This can be particularly hazardous at junctions where motor vehicles (particularly HGVs) are turning left placing the cyclist outside the drivers' central area of vision or in their blind spot.

The objective of this research, therefore, is to investigate the degree to which the presence of a cycle lane affects the amount of space demonstrated by a driver when passing a cyclist and whether or not the lane being coloured has an additional effect.

\section{Background}

The European Union (EU) recognises the multiple benefits of cycling in many documents, principally 'Cycling: the way ahead for towns and cities' (Dekoster, Schollaert 1999) and continues to support policies aimed at promoting cycling across Europe, having established initiatives such as Bike Week, CIVITAS and co-financed the ASTUTE, BYPAD, SPICYCLES and Velo Info projects. The CIVITAS (CIty VITAlity Sustainability) initiative (http://www.civitas-initiative.org) aims to assist European cities in achieving sustainable, clean and energy efficient transport systems. Within the 2004 White Paper, Scotland's Transport Future (Scottish Government 2004) the Scottish Executive's Transport Group (now the Scottish Government and Transport Scotland) presented five high level objectives of promoting Economic Growth and Social Inclusion through a Safe, Integrated and Environmentally friendly transport system. Whilst the importance that cycling has in all five of the objectives is recognised, the White Paper specifically considers that cycle lanes and other design and engineering measures can help to achieve the Safety objective 'encouraging more to walk and cycle every day'. The White Paper does not however give specific details of how the safety objective and other objectives are to be delivered with respect to cycling, other than to say cycling will be 'encouraged'.

Within the UK the main piece of legislation, concerning the provision for cyclists is the Local Transport Note (LTN 2/08) (Department for Transport 2008). This document recognises a clear hierarchy of provision that should be considered by traffic planners and engineers when it comes to providing for cyclists. Reallocation of road space (which may involve cycle lanes) is only the fourth item on the list, to be considered after volume reduction, speed reduction and junction improvement). Cycling Scotland also considers that this hierarchy is appropriate for use in the planning and engineering of cycle routes in Scotland (Cycling Scotland 2010). However, LTN 2/08 also recognises that items in the hierarchy are not mutually exclusive (for example reducing the volume of traffic may release carriageway space to provide cycle lanes) and it further recognises that whilst cycle lanes can benefit cyclists, poorly designed lanes can make conditions for the cyclist worse and there is no legal compulsion for the cyclist to use them. Furthermore, the note cites the position identified by Franklin (2007) within the National Cycle Training Standards on Bikeability, that unsuitable cycle lanes may encourage cyclists to adopt inappropriate positioning and, therefore, should ideally reflect the movement of cyclists and if necessary be placed in between motorised traffic lanes. Franklin also considers that many cycle lanes are misinterpreted by drivers as defining the space a cyclist needs and where lanes are narrow this can lead to faster and closer overtakes than if the lane had not been there. This is in agreement with Parkin and Meyers (2010) who demonstrates that drivers overtake in closer proximity in the presence of a cycle lane on higher speed roads.

Perceived risk (albeit incorrect) is the largest barrier when it comes to those contemplating cycling, or is a major deciding factor in the route choice of existing cyclists. As well as being recognised in current policy this has also been considered in studies by Hopkinson and Wardman (1996), and Wardman et al. (1997, 2000), etc. The 1996 study by Hopkinson and Wardman (1996) involved a general postal return questionnaire, which sought levels on cycle use and stated preference (home interview) surveys, as part of a review of cycling facilities in Bradford, West Yorkshire. In particular, the study found that safety is more valued than time when it comes to route selection by individual cyclists and promotes this as a basis of appraisal of cycling schemes. A stated preference study in the US, Tilahun et al. (2007) also suggested that cyclists valued perceived safety over time and would be willing on average to travel an additional 14-19 minutes to cycle on a road with cycle lanes compared to one without, depending upon the presence of car parking. The Wardman et al. (1997) study, again through a stated preference technique, examined the promotion of cycle lanes and cycle paths as tools to encourage cycling and to attain the then government's target of doubling cycle trips by 2002 and doubling them again by 2012. Although these targets were subsequently abandoned, it is important to note that the report concluded that facilities alone would be insufficient to overcome the perceived barriers and encourage a modal shift. Attitudes towards perceived risks were also quantified by Pearce et al. (1998) in a TRL study; $51.1 \%$ and $43.3 \%$ respectively of non-cycling adults perceived traffic en route and the lack of cycle routes/lanes to be barriers to 
cycling. A similar survey was carried out for the Cycling Action Plan for Scotland - CAPS (Scottish Government 2010a), however, percentages are far lower. Only 29\% of participants in the Scottish survey perceived danger from traffic as a reason not to cycle more and only $13 \%$ considered it a reason not to cycle (for comparison 11\% of participants cited driver behaviour as a reason not to cycle). Furthermore, only $7 \%$ of cyclists and $10 \%$ of noncyclists in the survey perceived the lack of road space for cyclists to be a barrier. More recently, Lawson et al. (2013) conducted a safety perception study of cyclists in Dublin (Republic of Ireland), surveying almost 2000 regular cyclists with a fixed response questionnaire, and developed a perceived safety model. Whilst non-cycling adults cite lack of infrastructure to be a barrier, the most frequent cyclists have the fewest safety concerns and lowest danger perceptions of cycling. The most frequent cyclists often preferred to cycle on road and were more concerned with surface quality than proximity to traffic. Beginner or learner cyclists, however, did show preference for segregated facilities and in general quiet roads with continuous cycle facilities were perceived as safer. Driver attitude was shown to be an important effect with reckless or careless behaviour having a strongly adverse effect on perceived safety.

Whilst all these studies suggest that the provision of cycle facilities such as cycle lanes can help to mitigate the perceived risk barrier and encourage cycling, it is postulated that what people say in qualitative studies and what people actually do in practice can be considerably different.

Parkin et al. (2007b) considered both links and junctions in an attempt to establish models of the perceived risk of cycling and its effect upon cyclist route choice. The study involved presenting video clips, observed from the point of view of a cyclist, to both cyclists and non-cyclists. The participants subsequently rated the clips on a scale of 1 to 10 relative to the risk they perceived. In contrast to the views presented by Hopkinson and Wardman (1996) and Wardman et al. (1997, 2000), the study found cycle lanes to have only a slight effect in reducing perceived risk and that they did not mitigate perceptions successfully when an entire cycle route was considered. Parkin considered that other factors such as the two-way flows and the number of parked vehicles en route also influenced the perceived risk. Parkin also discusses the cyclists' perception to infrastructure and discusses international attempts at establishing a 'bikeability' index.

The implication of cycle lanes on the lateral positioning of both bicycles and motor vehicles has been considered for some time, although until recently this has not been reflected in the aforementioned standards. Kroll and Ramey (1977) carried out a study which involved the filming of several urban streets, both with and without cycle lanes, in the United States of America and this was supplemented by data from three additional sites both prior and post construction of cycle lanes. The results in both parts of the study indicated that when cycle lanes are present, whilst the extremes in driver overtaking behaviour were reduced (with fewer close overtakes and wide swerves), the average overtaking distance did not vary. In contradiction to this it was, however, found that on certain streets a cycle lane reduced the overtaking distance demonstrated by drivers.

Also in the United States (Florida), Harkey et al. (1997) in an evaluation of cycle facilities videoed 13 sites, which had either a cycle lane, a paved hard shoulder or a wide curb lane (i.e. no cycle lane but wider inside lane, WCL) facility. Still pictures were also taken when a driver overtook a cyclist. The collected data, was subsequently used to establish a model, a Bicycle Compatibility Index (Harkey et al. 1998), which could be used by planners and engineers to determine the suitability of a road for cycling. The study found that the main variables affecting the separation distance between the cyclist and the overtaking vehicle were: the facility type, vehicle presence in the adjacent lane, the presence of an open drainage gulley, the number of lanes, the speed limit and the total width of the road. Significantly where the facility was a wide curb lane as opposed to a cycle lane the mean separation distance increased; it was also noticed that cyclists tended to be closer to the kerb at these sites. The study also found that the extent to which a driver deviated on encountering a cyclist appeared to be dependent upon the area, rural or urban, deviation being greater in rural settings rather than by facility.

Walker (2007) carried out a study with an instrumented bicycle, which recorded the proximity of a motor vehicle to a cyclist, and this was statistically compared to the position of the cyclist on the road. The study found that, contrary to common belief within the cycling community, drivers gave less room when overtaking a cyclist positioned further from the kerb. The study also demonstrated that a driver gave the cyclist less room where the cyclist was male or wearing a helmet. In addition drivers of buses or heavy goods vehicles also gave cyclists less room. The observed results suggested that drivers' tended to act on a preconception of cyclists and brief visual assumptions. However, the work did not appear to take account of the available carriageway width or link the data to speed or flows. The study also recommended that further investigation into the effects of cycle lanes on overtaking distances is required; perhaps considering the width of the lane.

Parkin and Meyers (2010) also collected quantitative data regarding the passing distances drivers demonstrate when encountering a cyclist. The Parkin study, however, considered passing distances relative to the presence or not of a cycle lane. The study examined three sites in Lancashire (two rural and one urban) whilst simultaneously reporting the recorded Annual Average Daily Traffic (AADT) flows at the sites. All cycle lanes used in the experiment were advisory and uncoloured. The analysis demonstrated that in rural environments (40 mph and $50 \mathrm{mph}$ zones) given a $9.5 \mathrm{~m}$ wide road, drivers demonstrated statistically greater overtaking distances in the absence of a sub-standard $1.45 \mathrm{~m}$ wide cycle lane (the Department for Transport (DfT) note 
recommends $2.0 \mathrm{~m}$ ). However, the findings were not replicated for a similar width road within an urban environment (30 mph zone), where there was found to be no significant difference between passing distances relative to the presence of $1.3 \mathrm{~m}$ (once more sub-standard) cycle lanes. Parkin suggests that where cycle lanes are present drivers may be driving within the confines of their own marked lane with less recognition being afforded to the cyclist.

Love et al. (2012) produced a linear regression model relating Vehicle Passing Distances (VPD) to quantitative variables; lane width, bicycle infrastructure, cyclist and street identity. Five cyclists (4 male, one female) used video recording methods to collect passing distance data in Baltimore Maryland (USA). The study was primarily investigating the compliance with a 'three-foot' bicycle passing law which had been implemented but which was un-assessed. The findings showed that in urban environments, increasing lane widths $(10 / 11 / 12 \mathrm{ft})$ resulted in average VPDs of 4.8/5.0/5.8 ft. The overall model had a fit $\left(R^{2}=0.26\right)$ of which $9 \%$ was explained by lane width. The cycle lane effect was positive explaining $8 \%$ of model variance-the cycle lanes were all of a fixed width in Baltimore and provided additional lane width to the standard road widths stated $(10 / 11 / 12 \mathrm{ft})$; it should be noted that UK cycle lanes are often of 'substandard' width (below DfT $2 \mathrm{~m}$ design guidance), so Walker, Parkin and Love's results may not be directly comparable. The gender effect of cyclist was consistent with Walker's results, but with insufficient data to be conclusive on this point. This study was not able to record traffic flow or speed data.

Chuang et al. (2013) investigated the effect of vehicle passing distance on the cyclists' behaviour, in terms of the cyclists' wheel angle, relative position and speed. Whilst road widths and cycle lane presence was not measured explicitly, the existence of a solid white line separating cyclists from motorised traffic was shown to have a positive effect on initial vehicle passing distance. This study used 38 cyclist participants riding instrumented bicycles to collect data and have demonstrated some of the adverse effects that insufficient passing distances can have on the cyclists. For instance, larger vehicles passing resulted in diminished lateral cycle stability (relative to passes by smaller vehicles), and slower passes (i.e. those of longer passing duration) resulted in the cyclists exhibiting less stable behaviours (relative to being passed more rapidly). The gender differences indicated in Walker's study are strongly supported with female riders being given significantly greater passing distances. The existence of a clear solid line of separation was shown to maintain a wider average separation and in addition was correlated with increased cycle stability, which would be expected to provide the cyclists with a more comfortable cycling experience.

The current design standards, whilst recognising the complications which may be associated with cycle lanes in terms of the cyclist's position and sub-standard widths etc., as presented by Franklin (2007), Parkin and Meyers (2010) and others mainly address the perceived benefits of cycle lanes. It is, however, theorised by this paper that (as suggested by the US studies) there are more significant factors affecting driver passing distances than the presence of cycle lanes. The current study will expand on the previous research in analysing cycle lanes of different colours and widths. Furthermore, it is considered that, given the aforementioned contradictions, further research is required into driver passing distances in order to gain a better understanding of the manoeuvre.

\section{Methodology}

\subsection{Equipment}

An instrumented bicycle was the main item used in the recording of vehicle overtakes of a pedal cycle (Ridgeback Velocity hybrid bicycle). Subsequently a AT1 wireless helmet camera was attached to the rear rack of the bicycle and was situated at a right angle to the direction of travel (as shown in Fig. 1a) so as to capture vehicle overtakes.

The camera initially recorded footage of a graduated board (scale) marked in $50 \mathrm{~mm}$ intervals from 0.5 $\mathrm{m}$ (from the bicycle tyre) to $2.5 \mathrm{~m}$, and to ensure consistency the scale was integrated into a specially constructed stand, which also held the rear wheel of the bicycle and a spirit level which was utilised to level the bicycle.

A second camera was also attached to the handle bar of the bicycle (ATC $5 \mathrm{~K}$ helmet camera). The ATC $5 \mathrm{~K}$ camera, shown in Fig. 1b, faced forward (the direction of travel for the bicycle) and was angled slightly towards the right so as to capture information such as the current flow conditions and the presence of parking (nearside or opposite) or other factors that would cause a temporary reduction in width (an opposing vehicle or traffic island). Furthermore, the second camera also recorded all overtakes, including those that were greater than the $2.5 \mathrm{~m}$ scale and which were not recorded by the first, sideways facing camera. The forward facing camera also clearly established vehicle types. Furthermore, the camera was also used to determine the time at which the cyclist passed fixed locations and hence the cycle speed. a)

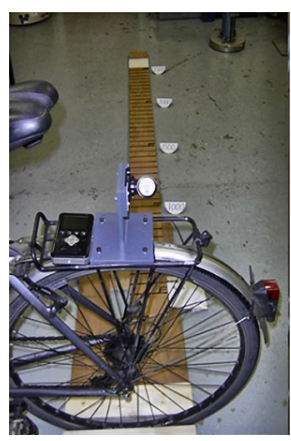

b)

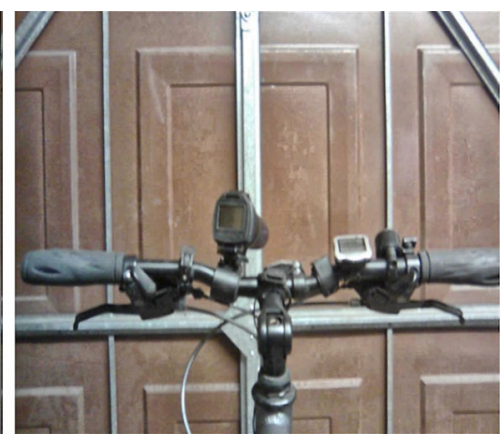

Fig. 1. Instrumented bicycle, AT1 camera/receiver, mount, cycle stand and graduated board (a) and ATC $5 \mathrm{~K}$ bar mounted camera (b) 
The cyclist wore the same trousers, jacket, and helmet at all times, and a small black pannier bag was attached to the left side of the bicycle rack to carry a notebook and a small digital camera. Whilst it was considered that this presented the image of the typical cycle commuter/utility cyclist, it was also considered that this consistent image would remove appearance as a possible variable.

\subsection{Survey Sites}

Between 4th October and 12th November 2010, between the hours of 10:00 and 16:00, 14 sites in Edinburgh (UK) were surveyed (with varying width and either without or with cycle lanes). The purpose of the data collection was twofold; to identify sites that were similar in nature in terms of width and traffic flow (both without and with cycle lanes, uncoloured and coloured) so that they could be statistically compared and to collect data from a range of sites in order to establish a Generalised Linear Model (GLM) of the overtaking process. Initial tests were also undertaken during the traditional AM (08:00-09:00) and PM (17:00-18:00) peak hours; however, this information was discarded as traffic conditions meant that the collection of flow data was impossible (i.e. dense traffic obscured the forward facing camera) and the cycle speed could not be consistent. Furthermore, traffic conditions were more unpredictable during this period and dangerous to the cyclist positioned only $500 \mathrm{~mm}$ from the kerb. As noted previously, more experienced cyclists generally consider that vehicles give them more space when they are further from the kerb and more visible, a view supported by Franklin (2007), Parkin and Meyers (2010) and others (but in contradiction to the findings of Walker (2007)).

Primarily sites were chosen so as to be straight and level as possible (so that these variables could be eliminated from the analysis) and furthermore this facilitated consistency in the data gathering (a constant cycle speed, etc.) and sites without and with (advisory) cycle lanes, coloured and uncoloured were selected. Sites were also chosen to be reasonably free of congestion, as this allowed efficient data gathering (at congested sites as previously stated, little or no data could have been reliably collected with the forward facing camera). Furthermore, sites were selected that were of continuous width, although individual sites were of various individual widths so that this variable could be modelled. Sites were also selected with different traffic flows, observed speeds, and with and without car parking, so that these variables could also be modelled.

The basic procedure involved the cyclist travelling at a consistent speed (in the region of $10 \mathrm{mph}$ ) between two fixed points at the selected sites. Runs were captured in both directions as it was considered that this was more efficient and would provide more balanced data with regard to vehicle flows. The forward facing camera capturing the aforementioned variables and corresponding still images extrapolated from the sideways facing (rack mounted) camera in order to determine vehicle overtaking distances.

\section{Analysis}

\subsection{Statistical Comparisons}

Three statistical comparisons were undertaken at:

- a site without cycle lanes to a similar site with uncoloured cycle lanes;

- a site with uncoloured cycle lanes and a site with coloured cycle lanes;

- a site without cycle lanes and a similar site with coloured cycle lanes.

An ' $F$ ' test was carried out in order to determine if there was a statistical difference in the variance of overtakes at such sites. A ' $z$ ' test (for $n>30$ ) or a ' $t$ ' test (for $n<30$ ) was then carried out to explore if there was a statistical difference in the means. A univariate ANOVA (Analysis of Variance) was also subsequently carried out to check the validity of the $t / z$ tests and to allow comparison with the previous reported tests, by Parkin and Meyers (2010) and Walker (2007). Vehicles observed overtaking by the front facing camera but not captured by the sideways facing camera (i.e. greater than $2.5 \mathrm{~m}$ ) were conservatively defined as $2.51 \mathrm{~m}$ overtakes and all tests were undertaken at a 95\% confidence level.

Selected sites were utilised for the comparisons (rather than an aggregate of all sites of a particular type) in order that similarities in terms of width, alignment and traffic flows could be maintained. Analysis was conducted for 'all vehicles' and separately for cars, LGVs and HGVs. Whilst tests could be conducted for LGVs and for HGVs at some sites, low numbers make these results inconclusive relative to cars and hence only all vehicles and car statistics will be reported.

\section{Comparison 1: No cycle lane vs uncoloured lane}

For the first of these comparisons, the overtaking distances observed on the $9.3 \mathrm{~m}$ wide section of Ferry Road, (without cycle lanes) were statistically compared with the overtaking distances that were observed on the $9.4 \mathrm{~m}$ Buccleugh Street site (with $2 \times 1.4 \mathrm{~m}$ wide uncoloured advisory cycle lanes). Other than similarities in width and alignment, however, both sites were also considered similar in terms of traffic flows (1256 vph, 7\% heavy compared to $1066 \mathrm{vph}, 5 \%$ heavy).

The results showed that whilst there was no statistical difference in the variances of overtakes between the two sites, for all vehicles and for car drivers alone, there was a statistical difference in the demonstrated mean overtaking distance (ANOVA: $P=0.0003$ for all vehicles and $P=0.0002$ for cars, respectively). As shown in Table 1, the mean overtaking distance for all vehicles was greater (by $0.16 \mathrm{~m}$ ) when a cycle lane was present.

The findings for car drivers are contrary to the findings of Parkin and Meyers (2010), who suggested that there was no difference at $30 \mathrm{mph}$ sites. It was noted, however, that $54 \%$ of vehicles were directly opposed by another vehicle travelling in the opposite direction at the Ferry Road site (without cycle lanes) compared to only $32 \%$ at the Buccleugh Street site (with cycle lanes). This variable was not recorded in the Parkin and Meyers (2010) study. Tests therefore were rerun removing this variable so as to investigate its importance. 
Table 1. Summary of statistical comparisons

\begin{tabular}{|c|c|c|c|c|c|c|c|c|}
\hline \multicolumn{2}{|c|}{ All vehicles } & \multirow{2}{*}{\multicolumn{2}{|c|}{ Mean overtake $[\mathrm{m}]$}} & \multirow{2}{*}{\multicolumn{2}{|c|}{ s.d. $[\mathrm{m}]$}} & \multicolumn{3}{|c|}{$P$-values } \\
\hline Comparison & Opposing traffic & & & & & $F$-test & $t / z$-test & ANOVA \\
\hline \multirow{2}{*}{1} & with & 1.84 & 2.00 & 0.34 & 0.32 & 0.2676 & 0.0001 & 0.0003 \\
\hline & without & 1.97 & 2.09 & 0.32 & 0.30 & 0.2743 & 0.0264 & 0.0310 \\
\hline \multirow{2}{*}{2} & with & 2.00 & 2.02 & 0.32 & 0.35 & 0.2277 & 0.7253 & 0.7270 \\
\hline & without & 2.09 & 2.09 & 0.30 & 0.35 & 0.1173 & 0.9943 & 0.9944 \\
\hline \multirow{2}{*}{3} & with & 2.04 & 2.02 & 0.26 & 0.35 & 0.0008 & 0.6310 & 0.6022 \\
\hline & without & 2.06 & 2.09 & 0.26 & 0.35 & 0.0042 & 0.5969 & 0.5600 \\
\hline
\end{tabular}

A reduced, but still statistically significant difference in the mean overtaking distance remained $(0.12 \mathrm{~m})$, (ANOVA: $P=0.0310$ for all vehicles $P=0.0138$ for cars). It is postulated that in an urban $30 \mathrm{mph}$ zone there are additional factors when a motor vehicle overtakes a cyclist which are more important than the presence of cycle lanes and that one of these may be the presence of an opposing vehicle (which can be much more variable in the urban setting).

\section{Comparison 2: Uncoloured cycle lane vs coloured lane}

Similar statistical tests were undertaken comparing Buccleugh Street $(9.4 \mathrm{~m}$ wide) with uncoloured cycle lanes $(2 \times 1.4 \mathrm{~m}$ wide) and Dalry Road (9.8 m wide) with coloured cycle lanes (1.6 m and $1.5 \mathrm{~m}$ wide). Flows are similar on average at the two sites (1066 vph as oppose to $807 \mathrm{vph}$ ) and importantly the percentage of opposing vehicles encountered by overtaking drivers is similar (32\%, as oppose to $30 \%)$.

The results of this test revealed a slight absolute difference in mean overtaking distance $(0.02 \mathrm{~m}$ more at the coloured site), but this was not a statistically significant difference for any vehicle category. The variances likewise showed no statistical difference.

The level of opposing traffic directly at the time of overtaking movements was similar at both the Buccleugh Street and Dalry Road sites (32\%, as opposed to $30 \%$ ), however, in the interests of consistency the tests were also repeated, removing that percentage of opposed traffic, so as to determine the effect of the colour of the cycle lane alone. No change in any of the statistical tests was observed.

\section{Comparison 3: No cycle lane vs coloured lane}

To further understand the effects of coloured cycle lanes upon overtaking distances, data gathered from the Muirhouse Parkway site (9.8 m wide with no cycle lanes) was statistically compared to data collected from the aforementioned Dalry Road site (also $9.8 \mathrm{~m}$ wide, with $1.5 \mathrm{~m}$ and $1.6 \mathrm{~m}$ cycle lanes). Whilst there was a difference in traffic flows at the two sites (on average $469 \mathrm{vph}$, as oppose to $807 \mathrm{vph}$ ), both flows similarly consisted of a large proportion of heavy vehicles (9\% compared to $12 \%$ most of which were buses), with both roads being located on busy bus routes.

Similar to the Parkin and Meyers (2010) study (albeit with coloured cycle lanes in this instance) the results demonstrated that there was no statistical difference in any vehicle categories in the urban $30 \mathrm{mph}$ environment, when it came to the mean passing distances $(0.02 \mathrm{~m}$ less at cycle lane site) that drivers presented when overtaking a cyclist regardless of the presence of a cycle lane. However, for this comparison a statistically significant difference in the variance of overtaking distance was observed opposite to that of Kroll and Ramey (1977) (s.d. = 0.26 for no-cycle lane vs $s . d$. $=0.35$ for cycle lane ( $F$-test: $P=0.0008)$. It is postulated that this variance was more likely to be due to the difference in vehicle flows, rather than the presence of the cycle lane.

Although both sites were considered low in terms of the percentage of vehicles directly opposing the overtaking vehicle (18\%, as opposed to $30 \%)$, for consistency statistical tests were also carried out removing these proportions. The results did not change in any notable manner.

The presented results demonstrated (in contrast to the previous study by Parkin and Meyers (2010), but in agreement with Love et al. (2012)) that at the investigated urban sites, overtaking distances were significantly increased when uncoloured cycle lanes were present compared to sites with no cycle lanes (Comparison 1). However, when uncoloured cycle lanes were compared to coloured cycle lanes there was found to be no statistical difference in the mean overtaking distance (Comparison 2). Furthermore, when a site with no cycle lane was compared to a site with coloured cycle lanes there was found to be no statistical difference in the mean overtaking distance, which is in agreement with the previous Parkin and Meyers (2010) study (Comparison 3).

This study, however, examined wider cycle lanes (1.4 m uncoloured cycle lanes and 1.5-1.6 m coloured cycle lanes as opposed to $1.3 \mathrm{~m}$ wide in the Parkin Study). It could be suggested from the analysed sites that drivers feel more certain as to the position of a cyclist on a road with coloured cycle lanes, whereas uncoloured lanes are less defined and hence drivers may be giving some additional space when the cycle lane is less clear. The analysis, however, also demonstrated that by removing the presence of opposing vehicles (those coming from the other direction and hence potentially limiting overtaking width) from the study and therefore considering only the effect of the cycle lanes, that the results were unchanged (although the strength of the significance level was decreased). 
Whilst the mean overtaking distance was not shown to be statistically different when comparing no cycle lane to a coloured cycle lane (Comparison 3), there was a significant difference in variance observed, with a higher standard deviation in overtaking distance in the presence of a coloured cycle lane.

\subsection{Generalised Linear Modelling}

The contrasting results of the statistical tests presented in Section 3.1 and previous literature suggests that within an urban area there are variables which may be more important than the presence of cycle lanes, affecting the distance a driver presents when overtaking a cyclist. The second part of this analysis investigates these possible variables in a Generalised Linear Model (GLM): where the overtaking distance (tyre to tyre) was the dependent variable and data was collected concerning: the absolute road width $[\mathrm{m}]$ lane width $[\mathrm{m}]$, vehicle type (Car, Taxi, LGV, HGV or Bus), the provision for cyclists (no cycle lane, cycle lane or cycle lane colour), cycle lane width $(\mathrm{m})$, factors temporarily reducing width (parking nearside/opposing, traffic islands or opposing vehicle), speeds (posted, cycle, relative or absolute, $\mathrm{mph}$ ) and traffic flows (opposing and 2 way average, vph) at the time of each individual overtake, which were analysed as possible independent variables.

The resultant model utilising 1908 measured overtakes (i.e. those overtakes $<2.5 \mathrm{~m}$ ) shown in Table 2, determined that the three most significant variables influencing the demonstrated overtaking distance were:

- Absolute Road Width [m];

- the presence of Parking [binary];

- the presence of an Opposing Vehicle [binary], where an increase in absolute road width increased overtaking distances, and conversely the presence of parking or an opposing vehicle reduced passing distances.

Vehicle Speed and Relative Speed were also discovered to be critical variables suggesting that faster motor vehicles tend to allow more room when overtaking a cyclist but that higher relative speeds (between bicycle

Table 2. Generalised Linear Model (GLM), constructed on recorded overtakes

\begin{tabular}{lccc}
\hline \multicolumn{1}{c}{ GLM-1 } & Coefficient & $t$-stat & $P$-value \\
\hline Absolute Road Width [m] & 0.058 & 13.070 & $1.92 \mathrm{E}-37$ \\
\hline Opposing Vehicle [binary] & -0.139 & -8.057 & $1.37 \mathrm{E}-15$ \\
\hline Vehicle Speed [mph] & 0.015 & 3.923 & $9.05 \mathrm{E}-05$ \\
\hline Relative Speed [mph] & -0.012 & -3.060 & $2.20 \mathrm{E}-03$ \\
\hline Nearside Parking [binary] & -0.235 & -8.703 & $6.88 \mathrm{E}-18$ \\
\hline Opposite Parking [binary] & -0.093 & -2.505 & $1.23 \mathrm{E}-02$ \\
\hline Colour of Cycle Lane & -0.036 & -2.298 & $2.17 \mathrm{E}-02$ \\
[binary] & -0.127 & -3.096 & $2.00 \mathrm{E}-03$ \\
\hline Presence of a Bus [binary] & $-6.56 \mathrm{E}-05$ & -3.340 & $9.00 \mathrm{E}-04$ \\
\hline Opposing Flow [vph] & 1.236 & 26.080 & $1.90 \mathrm{E}-128$ \\
\hline Intercept & & &
\end{tabular}

and motor vehicle) were correlated with a reduction in the overtaking distance.

The Opposing Flow [vph] at the time of the overtaking manoeuvre was also discovered to be critical, suggesting that logically as the opposing flow increases the overtaking distance decreases. It is hypothesised that this may be because when the road becomes busier, visibility is reduced and hence time for the driver to consider deviating from their path is reduced.

A surprising finding was that the binary variable representing the presence of buses was also critical. It is theorised that because the vast majority of buses in Edinburgh (Lothian Buses) are extremely consistent when it comes to overtaking a cyclist that this variable was identified as significant. The presence of Opposite Parking was also found to be significant within the model and was logical in terms of its influence, i.e. when it is present it results in a reduced effective width and less room for the driver to deviate when overtaking a cyclist.

Considered the least critical of the critical variables, was the presence of a Coloured Cycle Lane; the multiplier suggests that this actually has a slight negative effect in reducing overtaking distances. Although, the previous significance tests showed this to be non-statistical when examining mean overtaking distances other tests did, however, find that in some instances (e.g. Comparison 3) drivers tended to vary their overtaking distances more when a coloured cycle lane was present. It is, however, considered important that the final model did not include the variable concerning the presence of any Cycle Lane (including coloured and uncoloured); this variable was found to be non-significant and was removed during the model building process.

The overall fit of this model was limited $\left(R^{2}=0.275\right)$, the intercept being more significant than the independent variables, suggesting that there are other more important variables that were not recorded (e.g. driver behaviour characteristics). The model fit is, however, comparable to that achieved by Love et al. (2012). One item which may have resulted in an improved fit was to have measured overtakes greater than $2.5 \mathrm{~m}$; these are included (albeit as fixed values of $2.51 \mathrm{~m}$ ) in model 2 below. It is postulated that to achieve a substantially better fit that variables related to driver behaviour characteristics would need to be included; if the driver is going to give the cyclist lots of room/pass close they may well tend to do so regardless of the facilities in place (cycle lane or no cycle lane).

To examine the unmeasured overtakes (i.e. those $>2.5 \mathrm{~m}$ ) a second model was built based upon all of the 2837 overtakes observed (those $>2.5 \mathrm{~m}$ were again conservatively assigned as $2.51 \mathrm{~m}$ ). As the relative speeds and hence vehicle speeds of these overtakes were not known (33\% of the total) it was considered better to construct the model without these variables; the resultant model is shown in Table 3.

It is considered significant that this model (including overtakes $>2.5 \mathrm{~m}$ ) was identical (to the previous model) in what was considered to be the most sig- 
Table 3. Generalised Linear Model (GLM), constructed on all observed overtakes

\begin{tabular}{lccc}
\hline \multicolumn{1}{c}{ GLM-2 } & Coefficient & $t$-stat & $P$-value \\
\hline Absolute Road Width [m] & 0.063 & 11.795 & $2.22 \mathrm{E}-31$ \\
\hline Posted Speed Limit [mph] & 0.009 & 5.165 & $2.58 \mathrm{E}-07$ \\
\hline Opposing Vehicle [binary] & -0.156 & -9.544 & $2.87 \mathrm{E}-21$ \\
\hline Effective Lane Width [m] & 0.095 & 9.432 & $8.11 \mathrm{E}-21$ \\
\hline Cycle Speed [mph] & 0.014 & 3.580 & $3.00 \mathrm{E}-04$ \\
\hline Nearside Parking [binary] & -0.262 & -11.066 & $6.79 \mathrm{E}-28$ \\
\hline $\begin{array}{l}\text { Presence of Traffic Island } \\
\text { [binary] }\end{array}$ & -0.065 & -2.936 & $3.40 \mathrm{E}-03$ \\
\hline Cycle Lane Width [m] & 0.107 & 6.739 & $1.92 \mathrm{E}-11$ \\
\hline $\begin{array}{l}\text { Colour of Cycle Lane } \\
\text { [binary] }\end{array}$ & -0.067 & -4.123 & $3.84 \mathrm{E}-05$ \\
\hline Presence of a Bus [binary] & -0.124 & -3.515 & $4.00 \mathrm{E}-04$ \\
\hline Opposing Flow [vph] & $0.009 \mathrm{E}-02$ & -5.263 & $1.53 \mathrm{E}-07$ \\
\hline \begin{tabular}{l} 
Intercept \\
\hline
\end{tabular} & 0.585 & 9.640 & $1.17 \mathrm{E}-21$ \\
\hline
\end{tabular}

nificant factors. The three most critical variables in this model were again:

- absolute Road Width [m];

- the presence of Parking [binary];

- the presence of an Opposing Vehicle [binary].

The Relative Speed and Vehicle Speed variables (not recorded for $+2.5 \mathrm{~m}$ overtakes) were replaced within this model by the Posted Speed and Bicycle Speed variables. This is consistent with the previous model wherein faster drivers generally provided more space when overtaking a cyclist, however, the faster the cyclist is (i.e. the lower the relative speed) the overtaking distance also tends to increase. Opposing Flow [vph] remains a critical variable within the model and again logically as this value rises, overtaking distances tend to reduce.

The presence of a Bus was again found to be the only significant vehicle during analysis of the overtaking manoeuvre and as with the previous findings it was found to reduce the overtaking distance. The Opposite Parking variable became non-critical when data including overtaking distances greater than $2.5 \mathrm{~m}$ was used and was subsequently removed from the model.

As with the previous model, the presence of coloured cycle lanes on a road of consistent alignment, width and gradient (circa 0\%) was also found to be significant, whereby coloured cycle lanes actually reduce overtaking distances slightly. As previously noted, it could be hypothesised that drivers consider cyclists to be more defined in coloured cycle lanes and do not feel the need to give them further space and hence pass more closely.

New critical variables were introduced in this model, which included the significant proportion of overtakes that were greater than $2.5 \mathrm{~m}$. The effective lane width became statistically important (this is the effective width of a road lane where a cycle lane or hatching reduces it or the half width of the road where there is no cycle lane or hatching). Wherein the wider a road lane is, the greater the overtaking demonstrated by drivers. However, the Cycle Lane width variable (which reduces lane width) also became statistically significant which appears to suggest that cycle lanes are only effective in increasing overtaking distances when they are wide but when the road is also. This finding appears to correlate with the current DfT guidelines that when a road is too narrow for standard cycle lanes, cycle lanes should not be installed. The variable regarding the presence of a width restriction such as a Traffic Island also became statistically significant in the second model, resulting in a slight reduction in predicted overtaking distances. On site it was observed that drivers would often pass at two extremes when a traffic island was present, either close to the cyclist (to avoid the island) or close to island and further from the cyclist (presumably using it as a defined edge to drive beside).

Whilst the second model has a slightly better overall fit $\left(R^{2}=0.424\right)$ than the previous model (and the intercept is statistically less important) there still remains a large residual error, suggesting once more that there are one or more important variables that have not been recorded when it comes to demonstrated overtaking distances. Once more, it is postulated that this variable is the individual driver behaviour.

\section{Conclusions}

This paper has presented the actual benefits of cycling in terms of health, wealth and the environment, both to the individual and to the greater population and has reviewed current policy and standards. Previous research in the field of cycle lane provision has also been discussed, and whilst limited, was also found to be contradictory in parts. For instance, users of roads with cycle lanes reacted more positively towards them when asked about them in qualitative studies; whilst in some cases drivers demonstrated 'more risky' behaviour (speeding and closer overtakes) at sites with cycle lanes when it came to quantitative data gathering. Furthermore, Parkin and Meyers (2010) suggest that whilst at $40 \mathrm{mph}$ and $50 \mathrm{mph}$, statistically significantly reduced overtaking distances are resultant at sites with cycle lanes compared to sites without; there was no statistical difference at $30 \mathrm{mph}$ sites. In this work we suggest that there were important un-measured variables, especially in the urban $(30 \mathrm{mph})$ area that could influence results.

Results of initial testing, through statistical comparison, confirmed that variables other than the presence of a cycle lane in the urban area would influence the distance a driver demonstrates when overtaking a cyclist. For instance, whilst the analysis demonstrated that there could be a statistically significant difference in overtaking distance between sites without cycle lanes and sites with (i.e. Comparison 1), at other sites there was none (i.e. Comparison 3). These results were both contradictory and complimentary of previous studies, hence suggesting that in the urban area at least, there are more significant variables present than the presence of a cycle lane. It was postulated that one of these vari- 
ables may have been the presence of an opposing vehicle at the time of an overtaking manoeuvre and results demonstrated that this highly variable factor would be important in the urban area.

Further testing investigated, through the construction of a Generalised Linear Model (GLM), what some of these variables were most likely to be and investigated a wide range of physical variables. It was found that overtaking distances increased most significantly relative to the absolute width of a road and reduced relative to the presence of width restrictions such as parking or the aforementioned opposing vehicle. Furthermore, cycle lanes, unless sufficiently wide were shown to have little statistical effect and were only significant variables in GLM-2 (when overtakes greater than $2.5 \mathrm{~m}$ were included in the analysis). In fact, coloured cycle lanes appeared to reduce predicted overtaking distances slightly and it could be suggested that drivers consider cyclists to be more defined (and perhaps already protected) in coloured cycle lanes and therefore do not feel the need to give them further space and hence pass closer.

The modelling process also demonstrated that there were more unexplored potentially significant variables than the extensive physical variables used. It is postulated that one of these variables is the driver himself (i.e. driver behaviour) and it is recommended that further qualitative research is undertaken to investigate possible behavioural characteristics. Previous research, however, demonstrates that there is often an observed discrepancy in what people say in qualitative studies and what they do in practice (i.e. the gap between stated preference and revealed preference) and any further research needs to consider this. Furthermore, it is hypothesised that human nature and driver behaviour trends will vary from area to area, site to site and even by time of day (i.e. different driving cultures, congestion, or frustration during peak times) making it difficult to quantify on a basis that can be readily generalised and quantified.

Further research could also compare cyclists' perceptions of passing distances on sites with and without cycle lanes to measured overtaking distances, utilising the procedure established in this report. It is recognised, however, that cyclists are not a homogeneous group and the beginner/leisure/commuting/touring/cyclist etc., are likely to have different perceptions. However, where similar studies have been undertaken at public transport stops/stations investigating perceived and actual passenger waiting times, both prior and post the implementation of a Real Time Passenger Information (RTPI) systems; it has been routinely found that passengers can overestimate waiting times by circa $20 \%$ prior to installation of RTPI compared to post, despite actual times remaining constant (illustrating perception bias).

It is therefore concluded, that in the urban environment at least, there are more significant factors (road width, parking, opposing traffic etc.) encountered when a driver overtakes a cyclist mid-block than simply the presence or not of cycle lanes. As identified in the literature review one of the problems of cycle lanes is that they may wrongly influence the position of a cyclist at junctions and further quantitative research is required to determine the scope of this potentially fatal problem. In line with the more recent standard (LTN 2/08) this research supports that there should be a presumption against the automatic provision of cycle lanes when widths will be substandard as GLM-2 suggests that effective lane width may be critical. Furthermore, and again in line with the recent standards, in order to reduce perceived risk and encourage more cycling, it is recommended that reducing or calming of existing motorised traffic must be explored first, creating an attractive and welcoming environment. The results of the GLMs suggest than lane width is the most significant variable to achieve a sufficient vehicle passing distance, hence the provision of narrow $(<2 \mathrm{~m})$ cycle lanes by reallocating existing road space may be insufficient to ensure that cyclists receive sufficient clearance for their comfort and perceived safety. Reconsideration of the entire road design and further exploration of driver behavioural factors is required.

\section{References}

Cavill, N.; Davis, A. 2007. Cycling \& Health: What's the Evidence? Cycling England, London. 27 p. Available from Internet: http://www.ecf.com/wp-content/uploads/2011/10/ Cycling-and-health-Whats-the-evidence.pdf

Chuang, K.-H.; Hsu, C.-C.; Lai, C.-H.; Doong, J.-L.; Jeng, M.-C. 2013. The use of a quasi-naturalistic riding method to investigate bicyclists' behaviors when motorists pass, Accident Analysis \& Prevention 56: 32-41. http://dx.doi.org/10.1016/j.aap.2013.03.029

Cycling Scotland. 2010. Cycle Infrastructure Design: Hierarchy of Provision. Fact Sheet 04/09. Available from Internet: http://www.cyclingscotland.org/wp-content/uploads/2010/10/Heirarchy-of-Provision-04-09.pdf

Dekoster, J.; Schollaert, U. 1999. Cycling: the Way Ahead for Towns and Cities. European Commission. 61 p. Available from Internet: http://ec.europa.eu/environment/archives/ cycling/cycling_en.pdf

Department for Transport. 2008. Cycle Infrastructure Design. Local Transport Note 2/08. London, UK. 92 p. Available from Internet: https://www.gov.uk/government/uploads/ system/uploads/attachment_data/file/329150/ltn-2-08_Cycle_infrastructure_design.pdf

Franklin, J. 2007. Cyclecraft: the Complete Guide to Safe and Enjoyable Cycling for Adults and Children. 2nd edition. Stationery Office. $260 \mathrm{p}$.

Harkey, D. L.; Reinfurt, D. W.; Knuiman, M.; Stewart, J. R.; Sorton, A. 1998. Development of the Bicycle Compatibility Index: A Level of Service Concept. Final Report FHWARD-98-072. 116 p. Available from Internet: http://safety. fhwa.dot.gov/tools/docs/bcifinalrpt.pdf

Harkey, D. L.; Stewart, J. R. 1997. Evaluation of shared-use facilities for bicycles and motor vehicles, Transportation Research Record 1578: 111-118. http://dx.doi.org/10.3141/1578-14

Hopkinson, P.; Wardman, M. 1996. Evaluating the demand for new cycle facilities, Transport Policy 3(4): 241-249. http://dx.doi.org/10.1016/S0967-070X(96)00020-0

Kroll, B. J.; Ramey, M. R. 1977. Effects of bike lanes on driver and bicyclist behavior, Journal of Transportation Engineering 103(2): 243-256. 
Lawson, A. R.; Pakrashi, V.; Ghosh, B.; Szeto, W. Y. 2013. Perception of safety of cyclists in Dublin City, Accident Analysis \& Prevention 50: 499-511.

http://dx.doi.org/10.1016/j.aap.2012.05.029

Love, D. C.; Breaud, A.; Burns, S.; Margulies, J.; Romano, M.; Lawrence, R. 2012. Is the three-foot bicycle passing law working in Baltimore, Maryland?, Accident Analysis \& Prevention 48: 451-456.

http://dx.doi.org/10.1016/j.aap.2012.03.002

Noland, R. B. 1995. Perceived risk and modal choice: risk compensation in transportation systems, Accident Analysis \& Prevention 27(4): 503-521. http://dx.doi.org/10.1016/0001-4575(94)00087-3

Parkin, J.; Meyers, C. 2010. The effect of cycle lanes on the proximity between motor traffic and cycle traffic, Accident Analysis \& Prevention 42(1): 159-165. http://dx.doi.org/10.1016/j.aap.2009.07.018

Parkin, J.; Ryley, T.; Jones, T. 2007a. Barriers to cycling: an exploration of quantitative analyses, in Horton, D.; Rosen, P.; Cox, P. (Eds.). Cycling and Society, 67-82.

Parkin, J.; Wardman, M.; Page, M. 2007b. Models of perceived cycling risk and route acceptability, Accident Analysis \& Prevention 39(2): 364-371. http://dx.doi.org/10.1016/j.aap.2006.08.007

Pearce, L. M.; Davis, A. L.; Crombie, H. D.; Boyd, H. N. 1998. Cycling for a Healthier Nation. TRL Report 346. Transport Research Laboratory, Crowthorne, UK. 58 p.

Scottish Government. 2010a. CAPS: More People Cycling More Often. Cycling Action Plan for Scotland (CAPS). 49 p. Available from Internet: http://www.scotland.gov.uk/Resource/Doc/316212/0100657.pdf

Scottish Government. 2010b. Preventing Overweight and Obesity in Scotland: A Route Map towards Healthy Weight. 50 p. Available from Internet: http://www.scotland.gov.uk/Publications/2010/02/17140721/0

Scottish Government. 2004. Scotland's Transport Future: the Transport White Paper. Available from Internet: http:// www.scotland.gov.uk/Publications/2010/02/17140721/0

Scottish Government. 2009. The Scottish Health Survey 2008. A National Statistics Publication for Scotland. Available from Internet: http://www.scotland.gov.uk/Publications/2009/09/28102003/0

Scottish Parliament. 2009. Climate Change (Scotland) Bill. Available from Internet: http://www.scottish.parliament. uk/parliamentarybusiness/Bills/16147.aspx

Tilahun, N. Y.; Levinson, D. M.; Krizek, K. J. 2007. Trails, lanes, or traffic: Valuing bicycle facilities with an adaptive stated preference survey, Transportation Research Part A: Policy and Practice 41(4): 287-301.

http://dx.doi.org/10.1016/j.tra.2006.09.007

Tolley, R. 2008. Walking and cycling: easy wins for a sustainable transport policy?, in Docherty, I.; Shaw, J. (Eds.). Traffic Jam: Ten Years of 'Sustainable' Transport in the UK, 117-137. http://dx.doi.org/10.1332/policypress/9781847420732.003.0006

Turner, A. 2008. Interim advice by the Committee on Climate Change. Letter. Committee on Climate Change. Available from Internet: http://www.theccc.org.uk/wpcontent/uploads/2013/03/Interim-report-letter-to-DECCSofS-071008.pdf

UK Parliament. 2008. Climate Change Act 2008. Available from Internet: http://www.legislation.gov.uk/ukpga/2008/27/ contents
Walker, I. 2007. Drivers overtaking bicyclists: Objective data on the effects of riding position, helmet use, vehicle type and apparent gender, Accident Analysis \& Prevention 39(2): 417-425. http://dx.doi.org/10.1016/j.aap.2006.08.010

Wardman, M.; Hatfield, R.; Page, M. 1997. The UK national cycling strategy: can improved facilities meet the targets?, Transport Policy 4(2): 123-133. http://dx.doi.org/10.1016/S0967-070X(97)00011-5

Wardman, M.; Page, M.; Tight, M.; Siu, Y. 2000. Cycling \& Urban Commuting: Results of Behavioural Mode and Route Choice Models. Working Paper 548. Institute of Transport Studies, University of Leeds. 31 p. Available from Internet: http://eprints.whiterose.ac.uk/2074 